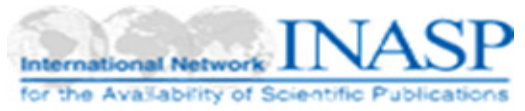

International Journal of Occupational Safety and Health, Vol 1 (2011) 3 - 4

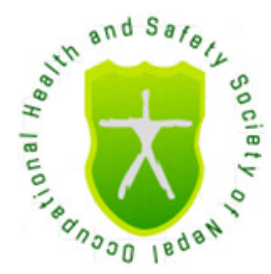

\title{
Congratulations on the new occupational health journal
}

\author{
Knut Skyberg MD, PhD \\ Dept. of Occupational Medicine and Epidemiology, National Institute of Occupational Health, Oslo, Norway.
}

On behalf of the colleagues within the field of occupational and environmental medicine in Norway, I would like to express my best wishes for the new journal. The International Journal of Occupational Safety and Health (IJOSH) is a big step forward for Nepal, and I am sure that this will contribute to the development of occupational safety and health in Nepal and other countries of the region.

As an active contributor to Ramazzini - the Norwegian Journal of Occupational Medicine, I have recently interviewed your Editor-in -Chief, Dr. Sunil Kumar Joshi about the development of occupational health in Nepal. I have learnt that there is a lot of interest for what is happening in countries like Nepal. One should bear in mind that the economic development in Norway has been very fast. Two or three generations back people in Norway experienced many of the same health problems that are common in Nepal today. We had malnutrition, increased child mortality, inadequate housing and infectious diseases like tuberculosis. As late as in 1935 we had 47 cases of leprosy. The same year 23,700 were under treatment for tuberculosis (Schiøtz C, editor. Textbook in Hygiene, 1938 - in Norwegian). Poliomyelitis was still a large problem during the 1950's. The working environment was often hazardous, with risks of injuries, silicosis and other pneumoconiosis and poisoning or skin damage from chemicals. Today our focus in preventive occupational medicine is more on work related diseases and rehabilitation. Still more traditional occupational diseases like asthma, chronic obstructive lung disorders, noise induced hearing loss and solvent induced encephalopathy are common. Some information may be found on the website of the European Agency for Safety and Health at Work (1).

Norway is a country that has been fortunate to have a lot of natural resources that modern societies ask for. Like Nepal, we have

(c) 2011 OHSSN All rights reserved. especially water resources and mountains, giving opportunities for hydroelectric power production. After the last World War (1939-1945) we were fortunate to receive major financial investments from the USA, Great Britain and France. We discovered oil in the 1970's. And fisheries have gradually been replaced by fish farming, an important export industry. But a problem for Norway and many other countries is that one is too dependent of raw material export. The further development of $\mathrm{Nepal}$ is of course dependent on a constructive political process, but there is no point in just waiting. It is important at the same time that education and research is stimulated, like the creation of this new medical journal. In addition, much can be done to develop the health standard in Nepal by non-governmental initiatives, like the work being done by the international organization Nyaya Health, currently running a hospital and a community health program in Bayalpata, north-western Nepal (2).

Norway is perhaps known for its international engagements, even though we are a small population of 5 million people. However, as a small country, we have learnt the importance of international collaboration. Within the field of occupational health we have been active in the International Commission of Occupational Health $(\mathrm{ICOH})$ and several subcommittees. In Europe, the European Union of Medical Specialists (UEMS) is important for our field as it has a section for Occupational Medicine (3). This section seeks to develop the standard of specialists in occupational medicine. This is crucial in a world with increasing movement of professional across the borders.

Research and publication are important activities to move forward any field of medicine. Documentation of the relationship between exposures in the work environment and adverse health effects provides the basis for preventive measures. Whenever possible, one should seek to document the positive effect of work environment improvements. As has been requested by the Cochrane collaboration, properly controlled intervention studies 
are missed within occupational medicine (4). Similar to controlled clinical trials, such studies are regarded as methodically superior to most other approaches. In addition, they provide a very pedagogic design that when successful may give motivation for further workplace developments. In addition to more traditional designs, it is my hope for this new journal that it will succeed in publishing studies showing development of the standard of the work environment and subsequent health improvements.

I wish the journal a prosperous future. Occupational health is still a relatively small discipline, and we need to build it step by step. In this global world it is possible to disseminate information quickly and effectively. I am sure many colleagues within this field will follow the journal closely.

\section{References:}

1. http://osha.europa.eu/fop/norway/en/index_html

2. http://www.nyayahealth.org/

3. http://www.uems-occupationalmedicine.com/dk/home

3.http://osh.cochrane.org/criteria-occupational-health-intervention -studies 